International Journal of Child, Youth and Family Studies (2013) 2: 259-273

\title{
RESILIENCE IN CHILD WELFARE: A SOCIAL WORK PERSPECTIVE
}

\section{Dermot J. Hurley, Lisa Martin, and Rhonda Hallberg}

\begin{abstract}
This study explores the concept of resilience as it is applied in child welfare practice from the perspective of front line child protection workers (CPWs). Specifically it examines how CPWs understand the concept of resilience and how they see themselves nurturing resilience in children and families. The paper also explores how working with resilient clients helps foster resilience in CPWs through a process of vicarious or shared resilience. This study is part of a larger three-site study conducted in Canada, Ireland, and Argentina examining the concept of resilience within specific socio-cultural contexts of child protection practice.
\end{abstract}

Keywords: resilience, child protection, vicarious resilience

Dermot J. Hurley, MSW, RSW (the Corresponding Author) is an Associate Professor at the School of Social Work, King’s University College at Western University, 266 Epworth Avenue, London, Ontario, Canada, N6A 2M3. E-mail: dhurley2@uwo.ca

Lisa Martin, MSW, RSW Child \& Family Mental Health, Child and Parent Resource Institute, London, Ontario, Canada. E-mail: lisa.martin@ontario.ca

Rhonda Hallberg, MSW, RSW is a Child Welfare Consultant, London, Ontario, Canada. E-mail: rhallber@uwo.ca 
International Journal of Child, Youth and Family Studies (2013) 2: 259-273

\section{Resilience}

The question of how children cope with adversity and develop competence and skills under difficult circumstances has been the subject of resilience research for some time. Resilience has been defined as "a dynamic process encompassing positive adaptation within the context of significant adversity” (Luthar, Cicchetti, \& Becker, 2000, p. 543). The concept has been extensively researched and there is a widely held view that resilience involves a complex interaction of individual characteristics and environmental factors within specific cultural contexts (Garmezy, 1985; Rutter, 1987; Werner \& Smith, 1992; Masten \& Coatsworth, 1998; Luthar et al., 2000; Ungar, 2004a). In a comprehensive review of resilience research and practice in the areas of developmental psychology and child welfare, Ann Masten (2011) notes that for decades the emphasis has been on enumerating risk and protective factors, understanding human adaptation, and articulating dynamic processes that trigger resilience. She points to a recent shift away from deficit-based to competence-based models of practice, and suggests that current efforts to promote resilience have in common a focus on positive indicators of adaptation, risk moderators, social development, and the quality of relationships (Masten, 2011). Other researchers suggest that a greater understanding of the social ecological roots of positive development is essential in promoting resilience (Ungar, 2011), which has particular relevance for disadvantaged child welfare populations.

\section{Resilience and Child Protection}

In the last decade there has been a concerted effort to introduce resilience concepts into child welfare practice. This has resulted in a number of studies enumerating various strategies to actively promote resilience in children at risk (Flynn, Dudding, \& Barber, 2006; Masten, 2006; Schofield \& Beck, 2005; Stein, 2006; Ungar, 2004a). The goal generally is to reduce risk or threat to children's development and increase positive adaptation through resilience-building interventions. Authors have emphasized the importance of promoting resilience in children in a variety of ways and settings: for example, mentoring talents and skills, (Gilligan, 2000); child care (Daniel \& Wassell, 2002); access to systems of care (Armstrong, Stroul, \& Boothroyd, 2005); child protection (Flynn et al., 2006); children, families, and communities (Dolan \& Canavan, 2008); and aboriginal youth in care (Filbert \& Flynn, 2010).

Common to these approaches is the application of resilience-based concepts in an effort to promote resilient functioning in children and youth. Some programs offer specific strategies for building resilience which can be applied in various settings. For example in the United Kingdom, Daniel and Wassell (2002) have developed a comprehensive and effective framework for promoting resilience which targets educational, social, relational, and personal assets (Daniel, 2006; Daniel \& Wassell, 2002). More recently their conceptual framework for resilience building has been successfully adapted for use in a statutory children's home in Northern Ireland (Houston, 2010).

Despite efforts being made to actively promote resilience in child welfare, authors have suggested that the concept of resilience is not well understood or articulated within the field of child protection and that there continues to be conceptual vagueness and lack of clarity in the application of resilience concepts. McMurray, Connolly, Preston-Shoot, and Wigley (2008) looked at how social workers constructed and utilized the concept of resilience in child welfare 
practice in the U.K. They found that social workers had difficulty conceptualizing resilience, and linking the concept to practice, and noted that "knowledge of the concept of resilience was generally derived from their everyday understanding rather than a policy-based or theoretical comprehension” (p. 307). Similarly, Daniel's (2006) research identifies a lack of knowledge of resilience theory among social work professionals, and notes the importance of integrating resilience concepts into assessment and intervention practice.

There is a continuing debate among researchers about the specific mechanisms that are likely to enhance resilience, which raises an important question about how child protection workers (CPWs) understand resilience and how they see themselves nurturing and enhancing resilience in their clients. High rates of emotional exhaustion and burnout among CPWs are well documented (Anderson, 2000; Corovic, 2006; Bride \& Figley, 2007) and of particular concern in a profession that seeks to promote stability and continuity in the lives of children at risk. CPWs deal with adversity in many forms and are impacted in a deep emotional way by exposure to severe conflict in child protection work (Ferguson, 2004). CPWs are confronted by extreme emotional pain and wrenching loss on a regular basis. Despite this, there is growing evidence to suggest that working with resilient clients can strengthen a worker's own resilience.

Hernandez, Engstrom, and Gangsei (2010) explored the idea of reciprocity in therapeutic relationships and described how witnessing clients overcoming adversity can change a therapist's "attitudes, emotions and behavior in ways that the authors conceptualized as manifesting vicarious resilience” (p. 72). Hence, the concept of vicarious resilience offers a unique perspective on how resilience in practitioners who are working daily with traumatized clients can be developed by proxy, through participation in the lives of resilient survivors of trauma and abuse (Hernandez, Gangsei, \& Engstrom, 2007; Alvarez \& Hurley, 2010).

\section{The Study}

This study is concerned with the question of what CPWs understand to be resilience and how they see themselves promoting resilience in children at risk. From a phenomenological perspective it explores three basic questions:

1. How is the concept of resilience understood within child protection practice?

2. What do CPWs see themselves doing to promote resilience in children and families?

3. How is the CPW impacted by the client's resilience?

From the authors perspective, child protection discourse in Canada, as in many other jurisdictions, has been dominated by deficit thinking and risk aversive practice which has been extensively critiqued in the U.K., Australia, and elsewhere (Lonne, Parton, Thomson, \& Harries, 2008). A resilience approach to child welfare practice is consistent with a strengths-based perspective and seeks to explore the link between resilience research and front line child welfare practice. Some new themes emerged from the study alongside those that had been identified in the literature adding an important dimension toward understanding resilience as a shared, mutually beneficial dynamic process between worker and client. 
International Journal of Child, Youth and Family Studies (2013) 2: 259-273

\section{Sample}

The research participants consisted of 20 social workers (10 BSW \& 10 MSW) ranging in age from 26 to 50, with between 3 and 22 years of experience in child welfare; 80\% of the respondents were female. All participating CPWs were employed at a Children's Aid Society in southwestern Ontario. Of the participants, over 90\% reported having removed a child on at least one occasion from a high-risk home and placing them in care. Caseloads ranged from 8 to 26 reflecting the diversity and complexity of practice within the agency. The sampling technique was purposive, ensuring that the child protection workers interviewed reflected a broad range of experience and years of service. Following a call for volunteers to participate in the project respondents were selected from adoption services, crisis intake, specialized foster care, family services, domestic violence, and sexual abuse teams. Purposive sampling allowed the researchers to select a wide range of participants with similar but quite distinct experiences within child welfare allowing for maximum variability within the study.

\section{Method}

The study employed semi-structured interviews based on questions related to how CPWs understand and utilize the concept of resilience in their work with children and families. Questions included in the interview guide were informed by the extant literature, feedback from a focus group session, and the extensive experience of the authors in child protection work. Ethics approval was granted by the Ethics Review Committee (ERC) of King's University College at Western University, as well as senior management at the participating agency. Written consent was received at the beginning of each interview, and a guarantee of confidentiality was provided. All the interviews were audiotaped and transcribed by research assistants.

\section{Data Collection and Analysis}

In-depth interviews (1 to 1.5 hours) were tape-recorded and transcribed verbatim. The interview guide allowed for some thematic consistency across interviews while preserving the uniqueness of each interview session. Data analysis and interpretation utilized a systematic approach for the management of textual data. The process involved careful reading of the text, coding, clustering topics, and identifying emergent themes (Cresswell, 2008). Content analysis was conducted manually, frequently with accompanying playback, in order to identify recurring patterns and themes in the interviews.

Drafts of all transcriptions were read independently by members of the research team to ensure that different points of view were fully explored before consensus was achieved on emerging themes and categories. Following transcription the researchers worked intensively with the text, coding the emerging themes and identifying patterns in the coded material. Discussion among team members enabled refining of coding frames, and initial themes emerged from the data, which were coded by team members using phenomenological bracketing.

Codes with similar content were clustered into categories from which final themes emerged. These were then organized into a framework with matched sections of text illustrating the main thematic findings. An independent audit was conducted by two colleagues (both professors of social work) who read segments of data and independently compared them with the 
International Journal of Child, Youth and Family Studies (2013) 2: 259-273

coding frames (inter-rater reliability was 0.85 ). Every effort was made to identify commonalities and contradictions between the respondents allowing for a fuller and more critical appraisal of emerging categories and themes. Care was taken to triangulate data via journal entries and field observations and member checking was undertaken with the respondents to ensure credibility and trustworthiness.

\section{Member Checking}

The principal investigator (PI) conducted all of the recorded interviews with a coinvestigator acting as an observer and note taker. The PI, a trained systemic family therapist with over 25 years experience in clinical interviewing, engaged the interviewee in prolonged collaborative open-ended discussion, frequently summarizing comments made by the participant in the form of ongoing informal member checking. Formal member checking occurred when the research team presented their initial findings to the host agency and invited the participants to comment on the initial themes that emerged in the research. This form of respondent validation via cross-checking interim research findings added greater authenticity to the study findings. Prior to the submission of the manuscript for publication, selective participants were contacted and asked to provide input on whether the final selection of themes accurately reflected what had been discussed in the interviews.

\section{Findings}

In this section of the paper the authors have chosen to use the exact words of the respondents which are presented in italicized speech and quotation marks interspersed with connecting commentary by the authors so as to maintain a sense of narrative flow and coherence.

\section{Constructing Resilience in Child Protection}

The construction of resilience among CPWs in the study is based on a number of ideas that are conceptually linked to practice. Resilience is seen as a multidimensional concept involving a complex interplay of family history, developmental factors, mental health, environmental and cultural influences. "Resilience is a very unique idea, I think it's a mixture of things like biology, environment, family development and culture”. Resilience is described as a universal attribute which requires the development of internal resources. "I think we're all born with different strengths and resilience is one of them, but you really have to work at it!" Universality was again underscored in the following statement: "every human being has something in there that's worth working with or exploring and having them build up some type of resilience to whatever life's thrown at them".

Genetic endowment was seen as significant in the development of resilience as is evident in the following: "it's not just the supports we put in place, a kid can be from an environment of severe neglect and one has this persistence and this tenacity which makes them very successful while another is still stuck at the start'. Resilience is conceptualized as a developmental process that builds over time, "resilience, for me is a continuum, I think it's about building on strengths that you have as an individual, a worker, a parent, or child, it relates to everybody". It is the ability to move forward despite adversity, "it's being able to manage to overcome difficult 
International Journal of Child, Youth and Family Studies (2013) 2: 259-273

situations in your life, so that when bad things happen, you're able to pick yourself up and get on with getting the best out of your life".

The willingness of families to acknowledge problems and accept support is a key element in what is viewed as resilient functioning. Any effort by the client to change the conditions that sap resilience is generally seen by CPWs as evidence of resilience at work. CPWs expect setbacks and are realistic about change, in fact the coupling of realism and resilience is central to how resilience is constructed by CPWs in the study, "even though she had serious mental health issues she worked with us and tried her very best to be there for her children". Clearly resilience is viewed as an ongoing process and a natural consequence of having to deal with adversity, which is why some CPWs emphasize the importance of resilient thinking when engaging clients, “you couldn't survive in this work if you hadn't got a resilience perspective”.

Data analysis revealed three overarching themes related to the construction of resilience by child protection workers, which include characteristics of the child, an enabling/dynamic relationship, and access to resources that enhance resilience.

\section{Characteristics of the Child}

Resilient children are seen as possessing tenacity and persistence based on temperament, traits, and genetic endowment. Characteristics most often noted about resilient children include stubborn determination, an ability to overcome the odds, a willingness to work on problems, and resourceful self-advocacy, "she had a strength about her that I thought, she's going to make it in the world, she somehow figured out from a young age what she had to do to survive, but I don't think she recognizes her own resilience". In contrast, some children are described as possessing greater self-reflection, "I think it's a child's view of themselves, it's the ability to see their strength(s) which is often demonstrated through an interest or skill or something else outside of the family".

Resilient children are able to remain connected to others in school and extracurricular activities and use resources effectively toward building a positive sense of their own identity. They are also seen as having some capacity for self-reflection and emotional regulation as long as essential contacts with family members are safeguarded, "I have this one boy who is still in care who's dealing with a lot of anger and resentment to mom who is a crack addict on the streets and he constantly worries about her safety and well-being but at least I can tell him that I know she's okay and that he'll see her again soon". Resilient children have a "sense of belonging" in their local community even when the relationship with biological parents is damaged or severed. "I had one client who used to talk about the lady who owned the pizza parlour across the street and when her mom was drunk and passed out she would go sit with this woman and watch her make pizza at her restaurant and that's what she remembers when you ask her who was the person who most influenced her in her life". Another worker offered a similar comment about a pre-teen girl she worked with for many years: "Throughout her time in foster care she remained involved with her mother's best friend from church and I believe her biggest strength today is the spiritual connection she has to her church". Such comments underscore the importance of understanding and preserving vital links in a child's social ecology in order to promote resilient functioning (Ungar, 2011). 
International Journal of Child, Youth and Family Studies (2013) 2: 259-273

Though these children have faced adversity and been hurt by it, "they try and live a normal life" despite numerous setbacks. Statements like, "she's been through so much, she can be very difficult to work with", add substance to the notion that resilient children can be challenging and are not always open to a therapeutic relationship. "I like you sometimes Eva but I hate that you're a child protection worker". They are often skilled at self-advocacy and are effective in getting their message across, "she can be very intimidating, but she knows her own mind and is able to get what she needs". Another worker spoke of an exceptional young girl in the following manner: "she was fascinating to me because she understood the system, she was a kid that was able to sit down and tell me how it felt to stand out, to be a foster child, she was very gifted verbally, she was a child that I thought to find an adoptive placement for because she was able to say that she wanted a family, I want somewhere I belong, I want to be out of the system".

Clearly there are limits to resilience and one worker remarked that "you can't develop resilience if you keep on getting knocked down...it's like an elastic band that can only be stretched so far, so many times". There is also the concern that too strong a focus on resilience can have negative implications since it suggests that children are invulnerable and can handle whatever adversity or stressors they may encounter in life. It is noted, with some irony, that there is greater expectations placed on children who are seen as resilient since typically they are more likely to be the first in a group of siblings to be returned to parents, which can inadvertently increase their risk for further maltreatment.

\section{An Enabling/Dynamic Relationship}

Resilience is related to traditional social work with families where collaboration, trust, and empathy are key ingredients of an effective working relationship. The emerging view is that resilience is seen as a dynamic relational phenomenon that develops through significant interactions with children and families over time. "We've had many ups and downs but I still feel connected to this family, even when mom is really depressed she makes an effort to work with us for the sake of the kids". It means being alert to possibilities for improving clients' lives by recognizing their personal resources, "you know despite the vulgar language she was very intelligent and articulate, people really liked her, sometimes I think she was a bit manipulative, but she made a really good impression at court”.

Child protection requires an emotional investment by the CPW in the context of mitigating risk and supporting resilience, "emotional support is so important in this work, just as much as safety and stability; I think she was so resilient because we were able to give her a lot of stability but we also gave her lots of support”. Continuing along this theme CPWs spoke about the importance of searching for resilient qualities in working with children and families. "The social worker has to see and promote strengths, ignoring these qualities makes no sense when working with families at risk”. There was a tendency among some CPWs to blur the conceptual boundary between strengths-based work and resilience concepts and they frequently used the words interchangeably. Supporting self-efficacy and family decision-making is a natural part of the resilience orientation of the CPW. It includes a notion of children developing the capacity for self-reflection and self-knowledge through the relationship with the worker, which is seen as fundamentally related to resilience building, "Resilience must be reflected, clients have to see it in themselves". 
International Journal of Child, Youth and Family Studies (2013) 2: 259-273

It's important to note that "there is no absolute standard to judge whether someone is resilient or not, some kids fall under the radar, we need to look at how we fail to see resilience". The importance of identifying what is sometimes referred to as "hidden resilience" (Ungar, 2004b) suggests that some behaviors deemed problematic by society can actually help children experience themselves as resilient. This belief is reflected in the following: "we have to help them to discover those talents and become aware of their abilities even if they are using those skills to engage in risk taking or anti-social behaviors".

Resilience is seen as dependent on relational process with key individuals in the child's world. In order to overcome the effects of abuse and victimization, a child or adolescent requires developmentally attuned adults who understand that promoting resilience is " $a$ step in a resilient chain". Resilience is not an end point in itself; rather it is an ongoing process that occurs in the context of caring and supportive relationships greatly facilitated by a secure attachment to parents or foster parents: "my role is to be a facilitator for that child, to have a healthy bonding relationship with whoever is going to be their caregiver...I tell my students you are not their parent, you are not their aunt or uncle, you are not their best friend because these kids are going to go through so much change, It's unfair to set them up to have a strong attachment to you".

Generally CPWs are aware that resilience is not a fixed quality and that it "waxes and wanes" with changing circumstances. They are also tuned into the idea that "lapses" in resilience can occur with loss of support and that resilient lacunae exist where a child shows resilience in one situation but not in another. These views accord well with the observation that resilient functioning is not necessarily even or consistent (Masten \& Powell, 2003)

The research revealed a good deal about the resilient relationship that can develop between the child and their CPW which is poignantly captured in the following statement: "for some reason she calls me every mother's day before she calls her mother and says 'I know you're not my mother but I just want you to know that you have been more of a mother to me in all those years that you worked with me than my mother ever has been"”. On the other hand, relationships with clients frequently test the resilience of both parties "I have to put clear boundaries in place with her...I tell her, 'you can't call me a bitch every day or tell me to f...off every day and expect that I'm going to be available to you 24/7..but I'd much rather you come to me as your support rather than taking it out on your kids"”.

\section{Access to Resilience-enhancing Resources}

The point was repeatedly made throughout the interviews that in order to be resilient, it's essential for families to be able to access key resources within their own community. CPW's appeared to understand the link between resilience and resources and work on behalf of their clients, particularly children in care, for academic, health, social, and recreational resources. One worker commented, however, that "resilience is not just about having resources, it's about using them effectively". All of the social workers interviewed spoke of the importance of access to family supports, child and adult mental health, and addiction services. In general, CPWs demonstrated persistence and tenacity in accessing resilience-enhancing resources tailored to a child's particular interests and circumstances, so for example a child could proclaim himself to be a "part of a dynamite travelling basketball team rather than a child in care". 
International Journal of Child, Youth and Family Studies (2013) 2: 259-273

One CPW with a background in banking spoke of the "price of resilience", meaning that accessing financial resources is key to enhancing resilience in children, "why not get the best that money can buy?....I would never send my own child to a second-rate music teacher, why would I do any less for my clients!". CPWs speak about the importance of making resources available to children for the purposes of nurturing resilience by "investing in whatever talents and skills a child has so that they can be developed further". Generally greater emphasis was placed on children's ability to utilize resources rather than linking resilience to the availability of resources, particularly for economically disadvantaged children living in high-risk communities.

\section{Nurturing and Promoting Resilience in Clients}

Building on the client's resilience is critical to resilience-based practice. For example, " $I$ like to think that I always go into my work believing that children are resilient, and that I can interject a positive person in that child's life, or do something to try to tap into that child's resilience to get them through". CPWs provided numerous examples of how they see themselves working to enhance resilience in the context of a dynamic enabling relationship within a child's social ecology. "I think resilience occurs when there's a relationship, or an interaction that is so positive for a young person that it enables them to move in a positive direction in their life,... this one child did so well because we were able to keep him with the same teacher for a number of years”. Clients are viewed as bringing resilient capacities into the relationship through selfreflection and insight. For instance, one worker talked about a parent who after many years of involvement with child protection came to terms with not being able to parent her children and supported a stable foster home placement for her children. Another worker spoke of a young child who came to the realization that her mother could not care for her and asked for input into her own adoption.

Many CPWs showed an understanding of the cumulative nature of resilience, "I don't have the grandiose idea that a 30-minute interview with me is going to build a lifetime of resilience... although you can help to build resilience over the long term by your input at key points". Persistence is also highly valued in the service of building resilience "it's very important to stick with it, especially when everything is falling apart”. An important aspect of supporting resilience for children in care is the crucial role of long-term workers who are guardians of narrative threads in the lives of children, providing essential continuity and meaning that would otherwise be lost in the frequent disruptions and relocations that are ubiquitous in child protection practice. One CPW described herself as "part of the living history of that child, kids are asking the worker stories about themselves when they were young, it's like holding on to the memories for the child which might easily be lost with moves from foster home to foster home". Another CPW remarked, "I'm reminded of situations where the social worker took all of the birthday photos, kept a journal, family heirlooms and bits and pieces that were very important to the child...the worker kept them all, she kept the child's memories safe".

There was an appreciation of the unique relationship that can develop between a child in care and a long-term CPW who can act as a container of narrative memories helping to preserve and retrieve vital self-narratives, providing a sense of continuity and connection, "we'd be making cookies and she'd ask me, 'what was I like as a baby, did I cry a lot?'”. There is an irony that resilience-enhancing resources are more often available to children who have been removed 
International Journal of Child, Youth and Family Studies (2013) 2: 259-273

from their family, as children in care generally have greater access to resources than children living in situations of marginal neglect or abuse. However resilience is more likely to flourish when the worker has been successful in preserving the social ecology of the child, which is often not the case. One worker in particular wondered if the child protection system overall does more harm than good which was expressed in the following quote: "I often ask myself are we doing a better job these days of promoting resilience or are we finding better ways to kill it?”, which is a reference to the many placements and CPW turnover, common in child protection practice.

Child protection work as a "vocation dedicated to helping clients discover their own resilience" was poignantly described in the following words: "I would love when I die that my clients might say! Maria was an encouraging person, someone who always saw the positive”. CPWs offered numerous examples of what they say and do in their work to promote and sustain resilience in their clients. For example, sharing their personal story, "sometimes I tell them about my own life as a teenager, I suppose I was resilient enough to cope with circumstances in my life, I look at young people the same way...you know what can I give them which will help get them through this period". CPWs understand the importance of cultivating a resilient perspective and being open to finding resilience in their clients as an antidote to a deficit-based discourse which is endemic in the field of child protection.

In summary, CPWs see themselves as nurturing resilience in children by being aware of the importance of resilience, by understanding resilience as a developmental process and by exposing children to resilience-enhancing activities within the social ecology of the child.

\section{How is the social worker's resilience impacted by the client's resilience?}

CPWs clearly enjoyed telling stories of positive outcomes in which resilience was a key component of their work and it was evident that the worker benefited from the process of sharing stories about resilient clients. For example, one social worker in the study captured the sentiment expressed by many others in the following account of an encounter with a client a long time after the termination of a case. "A few years ago I was out with my wife to a food court and there was a young man in his late 20s holding a baby in a really gentle way and my wife remarked that it was lovely to see a guy looking after a baby like that...; anyway I didn't know who this guy was until he came over and told me that he remembered me, and he actually said, 'I just want to thank you, I was hell on wheels in the group home, but there was a lot of things that I heard you say that really struck home later in life"'.

Resilience shared between the CPW and child or family is a dynamic process based on the idea that the worker receives in return something from the child or family that is not always recognized in child protection practice. A key finding in this study is the extent to which social workers themselves are impacted by their perception of client's resilience. This emerged in the form of stories regarding how clients overcame adversity and made positive changes in their lives. In this sense resilience can be viewed as a reflexive process with benefits for both parties involved. CPWs acknowledge that they learn a lot about their own lives by observing their clients and seeing how they manage their problems, "I've learned so much from my clients not just about what to avoid in life but how to be strong.... how to make the best of a terrible situation and still come out on top". There are also recognized benefits for the CPW from sharing success stories captured in the following: "good outcomes make our work worthwhile, it's important to 
International Journal of Child, Youth and Family Studies (2013) 2: 259-273

acknowledge the positive work we're doing and to celebrate our successes with the team". The benefits for the worker are acknowledged in phrases such as "they help us become better at our job" or self-reflexive statements such as "it forces us to dig deeper into our own emotional lives”.

There appears to be a bi-directional "transmission of resilience" in which both people in a relationship are affected by the resilience of the other. For example, a child might find in their worker a degree of persistence, tenacity, and commitment to them paralleled by the same qualities in the child directed towards their own family. One CPW described it as a "contagious process", meaning that resilience can be triggered by witnessing or participating in the performance of another person's resilience. CPWs also take vicarious pleasure in their client's successes and emotional growth and they are greatly heartened by stories of successful outcomes in which they themselves have participated. "If I have a young man or woman who was sexually assaulted as a child, who is now able to walk into a classroom and be successful, who can have friends that are healthy and not destructive, who can have a healthy relationship that is not power driven and abusive, to me that's something to celebrate because it means that they've overcome their victimization to be able to have some sort of a sense of self'.

\section{Discussion}

Resilience in this study is described as an innate human quality that can flourish in the face of adversity when facilitated within a social ecology that enables the development of resilient capacities. The concept is broad-based and includes ideas such as preserving attachments, strengthening social connections, accessing resources, and promoting successful outcomes. Resilience from a CPW perspective makes sense when it is applied to real life situations, where resources, skills, abilities, strengths, and possibilities are identified as essential ingredients of resilience-based practice. These finding are consistent with earlier resilience research and practice that offers evidence-informed strategies for enhancing resilience (Brooks \& Goldstein, 2002; Hart \& Blincow, 2007). Resilience for CPWs in the present study means building on the resourcefulness that individuals utilize in adverse conditions and facilitating the development of these capacities in whatever way they can. It is based on the view, widely held among CPWs, that children at risk can develop resilience despite situations of neglect, abuse, and deprivation. CPWs appear to have some conceptual basis for resilience practice though they do not utilize a critical social work theory perspective in discussing resilience in child welfare. Generally, there was not a lot of discussion about the problem of promoting resilience when resources are scarce, which is frequently the case for severely disadvantaged families and communities who are typically overrepresented in child welfare populations (Lescheid, Chiodo, Whitehead, \& Hurley, 2006)

The study also identified characteristics in children and families that social workers associate with resilience and examined how resilience is fostered in a dynamic enabling relationship between a child and a CPW. In this respect social workers are seen as having the potential to be part of a resilience-enhancing environment for child clients. CPWs look for " $a$ glimmer" of resilience in their clients, and they see themselves as "nurturing the seeds" of resilience through a dynamic enabling relationship and by accessing a variety of supports within the social ecology of the child. Resilience is related to the ability of CPWs to access resources to 
support the development of children's talents and skills. Ironically, it is the experience of many CPWs that these resources are made available after children have been removed from their families and are in the care of the child protection agency, which clearly has significant implications for child welfare policy and practice.

Resilience in child protection is viewed as a two-way relationship in which both participants can benefit from the strength and resourcefulness of the other. CPWs see themselves as supporting resilience by identifying and promoting resilience in their work with clients. This activity is recognized as being mutually beneficial, as supporting resilience in clients creates the potential for shared resilience to flourish. Though not labelled in this way by CPWs, there is an understanding that vicarious resilience is a natural consequence of participating in the resilience of others. It is a concept that requires a deeper understanding of resilience within the context of shared emotional experience. CPWs spoke about how they had been inspired and strengthened by their client's way of coping with adversity, and throughout the study it became obvious that this effect could be reinforced by consciously attending to it (Hernandez et al., 2007). The point was made in the study by a number of CPWs that nurturing resilience in children required CPWs to be resilient themselves so that a parallel process could be enacted thereby enabling the CPW to be more protective of the resilience of their clients.

\section{Limitations}

There are limitations to this study. There is the potential for the effect of professional bias, resulting in members of the research team being overly sympathetic to the experience of fellow social work professionals, perhaps at times minimizing problematic aspects of child protection practice. There may also be a tendency to reify resilience and ascribe greater significance to it than may be warranted, given the reality of child protection work and its attendant risks. The narrative excerpts show that the themes are not discrete and frequently overlap. It is important to acknowledge the anecdotal stories told about resilient clients as "evidence" of resilient functioning in the absence of more solid outcome data to support the observations made about resilient children. Also there is a "parallel discovery” process between theory and findings occurring throughout the study in relation to the concept of vicarious resilience which needs greater clarification. A further limitation of the study is that resilience work at the community level was not explored and a model of community-based intervention to enhance resilience would add a further dimension to intervention with children and families (Landau, 2007). Lastly, this research did not explore different manifestations of resilience, such as discontinuous, partial or situational, which would have enriched the data, and is an important area for further research. Despite these limitations the study recognizes that resilience-based child protection practice, which entails commitment, sensitivity, and ingenuity, is essential for promoting and sustaining resilience in children. 
International Journal of Child, Youth and Family Studies (2013) 2: 259-273

\section{References}

Alvarez, L., \& Hurley, D. (2010). Desde La zona de riesgo a la zona de resiliencia. RevistaCientifica de UCES, X1V (2)-Primavera, 13-36.

Anderson, D. G. (2000). Coping strategies and burnout among veteran child protection workers. Child Abuse and Neglect, 24(6), 839-848.

Armstrong, M. I., Stroul, B. A., \& Boothroyd, R. A. (2005). Intercepts of resilience and systems of care. In M. Ungar (Ed.), Handbook for working with children and youth: Pathways to resilience across cultures and contexts (pp. 387-405). Thousand Oaks, CA: Sage Publications.

Brooks, R., \& Goldstein, S. (2002). Raising resilient children: Fostering strength, hope and optimism in your child. New York: McGraw-Hill.

Bride, B. E., \& Figley, C. R. (2007). The fatigue of compassionate social workers: An introduction to the special issue on compassion fatigue. Clinical Social Work Journal, 35(3), 151-153.

Corovic, T. (2006). Child protection workers and vicarious trauma: A view from the edge. Ontario Association of Children's Aid Societies Journal, 50(1), 11-15.

Creswell, J. W. (2008). Research design: Qualitative, quantitative, and mixed methods approaches. Thousand Oaks, CA: Sage Publications.

Daniel, B. (2006). Operationalizing the concept of resilience in child neglect: Case study research. Child: Care, Health and Development, 32(3), 303-309.

Daniel, B., \& Wassell, S. (2002). Adolescence: Assessing and promoting resilience in vulnerable children 3. London: Jessica Kingsley Publishers.

Dolan, P., \& Canavan, J. (Eds.). (2008). Special Issue: Building resilience in children, families and communities. Child Care in Practice, 14(1).

Ferguson, H. (2004). Protecting children in time: Child abuse, child protection and the consequences of modernity. Basingstoke, UK: Palgrave MacMillan.

Filbert, K. M., \& Flynn, R. J. (2010). Developmental and cultural assets and resilient outcomes in First Nations young people in care: An initial test of an explanatory model. Children and Youth Services Review, 32(4), 560-564.

Flynn, R. J., Dudding, P. M., \& Barber, J. G. (Eds.). (2006). Promoting resilience in child welfare. Ottawa, ON: University of Ottawa Press.

Garmezy, N. (1985). Stress-resistant children: The search for protective factors. In J. E. Stevenson (Ed.), Recent research in developmental psychopathology. Journal of Child Psychology and Psychiatry Book Supplement No. 4 (pp. 213-233). Oxford: Pergamon Press. 
International Journal of Child, Youth and Family Studies (2013) 2: 259-273

Gilligan, R. (2000). Promoting resilience in children in foster care. In G. Kelly \& R. Gilligan (Eds.), Issues in foster care: Policy, practice and research (pp. 107-126). London: Jessica Kingsley.

Hart, A., \& Blincow, D. (2007). Resilient therapy: Working with children and families. London: Taylor \& Francis.

Hernandez, P., Engstrom, D., \& Gangsei, D. (2010). Exploring the impact of trauma on therapists: Vicarious resilience and related concepts in training. Journal of Systemic Therapies, 29(1), 67-83.

Hernandez, P., Gangsei, D., \& Engstrom, D. (2007). Vicarious resilience: A new concept in work with those who survive trauma. Family Process, 46(2), 229-241.

Houston, S. (2010). Building resilience in a children's home: results from an action research project. Child and Family Social Work, 15(3), 357-368.

Landau, J. (2007). Enhancing resilience: Families and communities as agents for change. Family Process, 46(3), 351-365.

Lescheid, A., Chiodo, D., Whitehead, P., \& Hurley, D. (2006). The association of poverty with child welfare service and child and family clinical outcomes. Community, Work and Family Journal, 9(1), 29-46.

Lonne, B., Parton, N., Thomson, J., \& Harries, M. (2008). Reforming child protection. London: Routledge.

Luthar, S. S., Cicchetti, D., \& Becker, B. (2000). The construct of resilience: A critical evaluation and guidelines for future work. Child Development, 71(3), 543-562.

Masten, A. S. (2006). Promoting resilience in development: A general framework for systems of care. In R. J. Flynn, P. M. Dudding, \& J. G. Barber (Eds.), Promoting resilience in child welfare (pp. 3-17). Ottawa, ON: University of Ottawa Press.

Masten, A. S. (2011). Resilience in children threatened by extreme adversity: Frameworks for research, practice, and translational synergy. Development and Psychopathology, 23(2), 493-506.

Masten, A. S., \& Coatsworth, J. D. (1998). The development of competence in favorable and unfavorable environments. American Psychologist, 53(2), 205-220.

Masten, A. S., \& Powell, J. L. (2003). A resilience framework for research, policy, and practice. In S. S. Luthar (Ed.), Resilience and vulnerabilities: Adaptation in the context of childhood adversities (pp. 1-25). New York: Cambridge University Press.

McMurray, I., Connolly, H., Preston-Shoot, M., \& Wigley,V. (2008). Constructing resilience: Social worker's understandings and practice. Health and social care in the community, 16(3), 299-309. 
International Journal of Child, Youth and Family Studies (2013) 2: 259-273

Rutter, M. (1987). Psychosocial resilience and protective mechanisms. American Journal of Orthopsychiatry, 57(3), 316-331.

Schofield, G., \& Beck, M. (2005). Risk and resilience in long-term foster care. British Journal of Social Work, 35(8), 1283-1301.

Stein, M. (2006). Resilience and young people leaving care: Overcoming the odds. York, UK: Joseph Rowntree Foundation.

Ungar, M. (2004a). A constructionist discourse on resilience. Youth Society, 35(3), 341-365.

Ungar, M. (2004b). Nurturing hidden resilience in troubled youth. Toronto: University of Toronto Press.

Ungar, M. (2011). The social ecology of resilience: Addressing contextual and cultural ambiguity of a nascent construct. American Journal of Orthopsychiatry, 81, 1-17.

Werner, E. E., \& Smith, R. S. (1992). Overcoming the odds: High risk children from birth to adulthood. Ithaca, NY: Cornell University Press. 